\title{
A comparative study on the functional outcome of intertrochanteric fractures treated by proximal femoral nailing or dynamic hip screw fixation
}

\author{
Gineshmon Chandy, Saju S.*
}

Department of Orthopedics, Government Medical College, Kottayam, Kerala, India

Received: 30 September 2020

Accepted: 03 November 2020

*Correspondence:

Dr. Saju S.,

E-mail: drsajus@yahoo.com

Copyright: ( ) the author(s), publisher and licensee Medip Academy. This is an open-access article distributed under the terms of the Creative Commons Attribution Non-Commercial License, which permits unrestricted non-commercial use, distribution, and reproduction in any medium, provided the original work is properly cited.

\begin{abstract}
Background: Intertrochanteric fractures are one of the commonly occurring injuries in elderly patients and are high among females and those with osteoporosis. They were treated with either dynamic hip screw (DHS) fixation or proximal femoral nailing (PFNA2) here at our institution. The study was conducted in order to find which method of surgical fixation has better functional outcome.

Methods: Total 96 patients of intertrochanteric fractures admitted during the study period of November 2017 to April 2019 were included for the study. These patients were randomly divided into two groups; DHS was used as implant in group1 and PFNA2 in group 2. Postoperatively patients were followed up after 1 month, 3 months and 6 months of the surgery and were assessed using Harris hip score.

Results: Harris hip score was higher with PFNA2 group compared to DHS group in all follow-ups. In unstable fractures DHS group had poor outcome compared to PFNA2. Radiological union occurred in $27.1 \%$ cases by 3 months and $72.9 \%$ cases by 6 months with DHS whereas $70.8 \%$ and $97.9 \%$ respectively with PFNA2.

Conclusions: PFNA2 gives a better functional outcome when compared to DHS. Even though DHS gives good functional outcome in stable fractures it is not so in the case of unstable fractures. The radiological union also is faster with proximal femoral nailing. Hence in our opinion PFNA2 can be the better fixation device compared to DHS especially in unstable fractures.
\end{abstract}

Keywords: Intertrochanteric fracture, Dynamic hip screw, proximal femoral nail anti-rotation

\section{INTRODUCTION}

Intertrochanteric fractures (IT) are commonly seen in patients over 70 years of age, mostly due to trivial trauma. ${ }^{1}$ Incidence has increased primarily due to increasing lifespan \& more sedentary life style brought by urbanization.1 In younger population, IT fracture occurs due to high velocity trauma compared to fractures in elderly which commonly occurs due to osteoporotic changes. ${ }^{1,2}$ This fracture is more in females compared to males due to osteoporosis. Mortality rates in intertrochanteric fractures is comparatively high among elderly $(>30 \%$ in the first year) IT fractures were previously managed by conservative methods which included traction, bed rest for 12-15 weeks followed by lengthy programme of ambulation and gait training which lead to high mortality rates and complications like bedsore, aspiration pneumonia, urinary tract infections, joint contractures, thromboembolic complications and shortening. ${ }^{3-5}$ The high rates of mortality and complications occurring in conservative management led to surgical interventions as being the preferred mode of management for IT fractures .

Internal fixation and early mobilization are currently the standard method of treatment. These fractures can be 
managed by different types of implants like dynamic hip screw (DHS), blade plate, proximal femoral locking plate, gamma nail, proximal femoral nail (PFN) and Proximal femoral nail anti-rotation Asia (PFNA2). ${ }^{6-12}$ Broadly the implants can be divided into Intramedullary and extramedullary devices. Extramedullary devices comprise of DHS, blade plate and proximal femoral locking plate. DHS is a commonly used implant in management of intratrochanteric fractures which allow collapse at the fracture site, leading to fracture union. Yet this line of management has its own disadvantages.

It is an open procedure with larger incision, increased soft tissue dissection, blood loss and increased operating time. In some occasions it allows uncontrolled collapse leading to failure. This procedure also takes longer time for mobilization.

Proximal femoral nail which is an intramedullary device became popular because of these drawbacks. PFN allows controlled collapse which is limited by its intramedullary location leading to less shortening. It can be done with a small incision, less soft tissue dissection and less blood loss. It allows patient for early mobilization as it is a load sharing device. But it has two screws to be put to the head of femur which is difficult in narrow neck of femur cases and takes more time to do that. It has other complications like screw cut out, backout ( $\mathrm{Z}$ effect) and varus collapse.

Proximal femoral nail anti-rotation (PFNA) was introduced by AO in 2003 in which srews were replaced by a helical blade. Helical blade impacts the cancellous bone around it when it is driven in which increases the femoral head strength as well as stability of fixation. It can be inserted without reaming out bone from head and neck region thereby giving more anchorage especially in osteoporotic fractures. PFNA2 was introduced for Asian population who has comparatively smaller femur. ${ }^{13,14}$

In view of these conditions, this study is taken up to compare the results of DHS and PFNA2 in the treatment of intertrochanteric fractures.

\section{Objectives}

Objectives were to compare the functional outcome in patients with intertrochanteric fractures treated by DHS fixation or PFNA2 and to compare radiological union at fracture site occurring with the two internal fixation devices used to treat similar kind of fractures.

\section{METHODS}

\section{Study design}

Prospective, Observational study period of July 2018 April 2019.

\section{Study population}

All patients with type I, type II or type III intertrochanteric fractures undergoing PFNA2 or DHS fixation in the Department of Orthopaedics, Government Medical College Kottayam from July 2018 to April 2019. A total of 96 patients were taken as the sample considering $\mathrm{Z} 1-\alpha / 2$ as $1.96, \mathrm{Z} 1-\beta$ as $0.82, \mathrm{p} 1=0.66$ and $\mathrm{p} 2=0.375 .15$ Patients were divided to two groups of 48 each for DHS and PFNA2.

\section{Study procedure}

Institutional ethical clearance was obtained for the study. After obtaining informed written consent, patients with type I, type II and type III intertrochanteric fractures (Boyd and Griffin classification) who were independent ambulators before the injury were enrolled in the study.16 Those patients with arthritis of the hip, other joint pathologies of the hip, pathological fractures and other fractures of the same limb were excluded. Sociodemographic and clinical data including age, gender, type of facture and pre injury ambulatory status was collected on a pretested and structured proforma. Implant selection for the surgery was done based on the operating surgeon's decision. Patient was positioned on the fracture table and traction was applied, fracture reduction confirmed under image intensifier following which DHS or PFNA 2 standard procedures were performed. If satisfactory reduction was not obtained for the PFNA 2 procedure by closed means, mini open technique was used for obtaining reduction and proceeded with nailing.

All the patients underwent standard rehabilitation protocol. They were started mobilization on 2 nd postoperative day with quadriceps strengthening exercise, knee and ankle mobilization. Drains were removed after 24 hours. Wound inspection was done on 3rd postoperative day. Stitches were removed after 10th postoperative day. Postoperative follow-up was done at 1 month, 3 months, 6 months following surgery and scores evaluated by Harris hip score (HHS).17 Radiographs of fracture were taken at the end of 3 months and 6 months to assess whether union has occurred.

\section{Statistical analysis}

The results were entered in MS excel version 3.4.1 and analysed using SPSS version 20. Quantitative variables were summarized as mean and standard deviation whereas qualitative variables were expressed as percentages and proportions. Using Harris hip score the functional outcome has been classified as excellent (90-100), good (80-89), fair (70-79) and poor (<70). Quantitative variables were compared using unpaired Student's t test/Mann Whitney U test. The qualitative variables were compared with Chi square test/Fisher's exact test. $\mathrm{P}$ value $<0.05$ was considered to be significant. 


\section{RESULTS}

The age of the patients in the present study ranged from 46 to 80 years with mean age of 69.25 years in case of DHS and a mean age of 58.65 for PFNA2. Majority of the patients were females in both the DHS group (58.3\%) and the PFNA2 group (54.2\%). Based on Boyd and Griffin's classification, the Type I fracture has been placed under stable fractures and type II and Type III as unstable. The current study has included 69 stable intertrochanteric fractures and 27 unstable fractures. Of the total cases done by DHS, $72.9 \%(n=35)$ were stable fractures, and $27.1 \%$ $(\mathrm{n}=13)$ being unstable. For the PFNA2 group, $70.8 \%$ $(n=34)$ were stable and $29.2 \%(n=14)$ were unstable intertrochanteric fractures.

Radiological outcome evaluation revealed $70.8 \%$ union in the PFNA2 group at 3 months and $97.9 \%$ union at 6 months as against lesser rate of union among the DHS group (Table 1). In case of unstable fractures out of the 13 cases treated with DHS, fracture site union could not be established in 5 cases even after 6 months in contrast to only one case that didn't unite in the PFNA2 group.

Table 1: Radiological outcome evaluation.

\begin{tabular}{|c|c|c|c|c|}
\hline & $\begin{array}{l}\text { Type of } \\
\text { implant }\end{array}$ & United & $\begin{array}{l}\text { Not } \\
\text { united }\end{array}$ & P value \\
\hline \multirow{2}{*}{$\begin{array}{l}3 \\
\text { months }\end{array}$} & DHS & $\begin{array}{l}13 \\
(27.1 \%)\end{array}$ & $\begin{array}{l}35 \\
(72.9 \%)\end{array}$ & \multirow{2}{*}{$0.001 *$} \\
\hline & PFNA2 & $\begin{array}{l}34 \\
(70.8 \%)\end{array}$ & $\begin{array}{l}14 \\
(29.2 \%)\end{array}$ & \\
\hline \multirow{2}{*}{$\begin{array}{l}6 \\
\text { months }\end{array}$} & DHS & $\begin{array}{l}35 \\
(72.9 \%)\end{array}$ & $\begin{array}{l}13 \\
(27.1 \%)\end{array}$ & \multirow{2}{*}{$<0.01 * *$} \\
\hline & PFNA2 & $\begin{array}{l}47 \\
(97.9 \%)\end{array}$ & $1(2.1 \%)$ & \\
\hline
\end{tabular}

*Chi square test, ** Fisher's exact test

Functional outcome of the patients assessed with Harris hip score (HHS) for both groups have been compared at 1 , 3, 6 months and the details are given in Table 2. A higher average HHS is evidently seen ( $p$ value $<0.05$, Mann Whitney U test) across the months of follow up.

Table 2: HHS at 1, 3 and 6 months.

\begin{tabular}{|llllll|}
\hline \multirow{3}{*}{ 1 month } & Groups & N & Mean & Std. Deviation & P value \\
& DHS & 48 & 36.21 & 5.078 & $<0.01 *$ \\
\cline { 2 - 5 } & PFNA2 & 48 & 46.31 & 4.825 & $<0.01 *$ \\
\hline \multirow{2}{*}{ 3 months } & DHS & 48 & 53.67 & 5.836 & $<0.01 *$ \\
\cline { 2 - 5 } & PFNA2 & 48 & 67.69 & 4.964 & 6.934 \\
\end{tabular}

* Mann Whitney U test

Table 3: Outcomes with methods of fixation.

\begin{tabular}{|lllll|} 
& DHS & & PFNA2 \\
& Stable & Unstable & Stable & Unstable \\
\hline Excellent & 0 & 0 & 6 & 0 \\
\hline Good & 23 & 1 & 25 & 11 \\
\hline Fair & 4 & 7 & 3 & 3 \\
\hline Poor & 8 & 5 & 0 & 0 \\
\hline Total & 35 & 13 & 34 & 14 \\
\hline
\end{tabular}

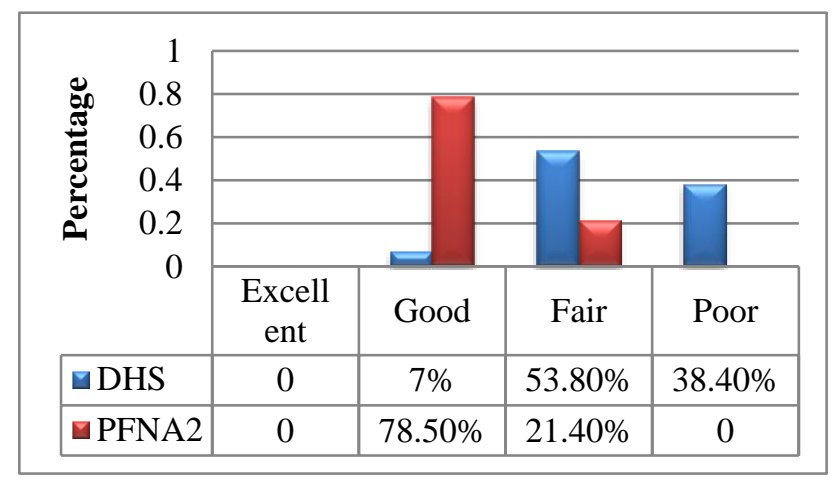

Figure 1: Functional outcome in unstable inter trochanteric fractures.
The functional outcome when classified using HHS was $62.5 \%$ (good), $10.4 \%$ (fair) and $27.1 \%$ (poor) for DHS group whereas $12.5 \%$ (excellent), $75 \%$ (good), $12.5 \%$ (fair) for PFNA2 group. In case of unstable fractures DHS group had 1 (good), 7 (fair) and 5 (poor) results out of 13 patients. When compared to this PFNA2 group had 11 (good) and 3 (fair) results out of 14 patients (Table 3 ).

\section{Case 1}

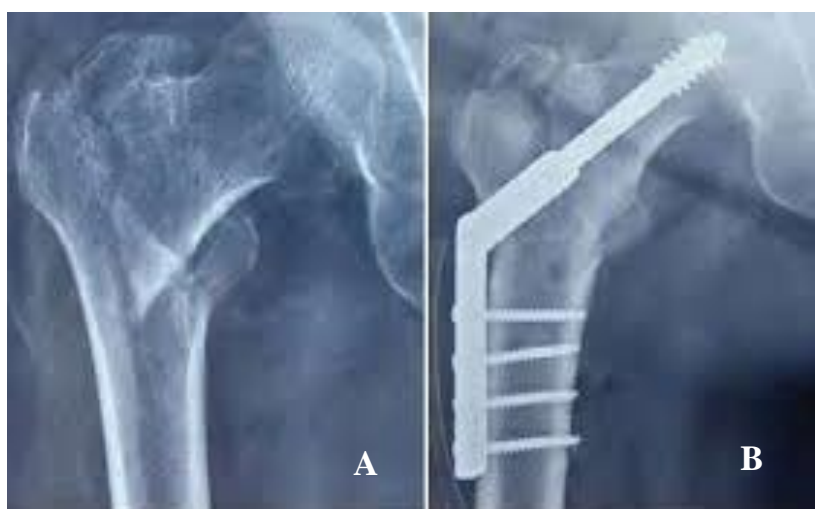

Figure 2: Dynamic hip screw -(A) Pre-operative (B) Post-operative follow up after 6 months. 
Case 2
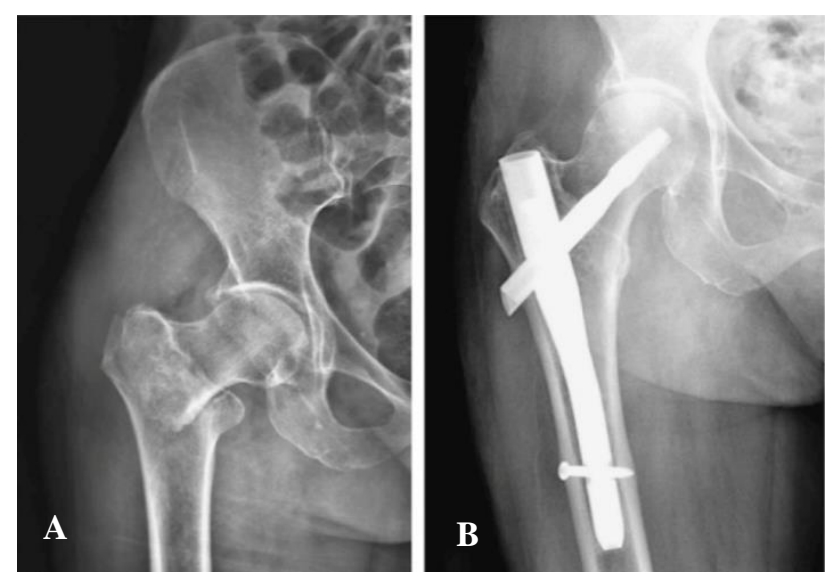

Figure 3: Proximal femoral nailing (A) pre-operative (B) post-operative follow up after 6 months.

\section{DISCUSSION}

During the past 3 decades, the incidence of colorectal Intertrochateric fractures are one of the common fractures especially in the elderly anywhere in the world. The treatment options for managing these fractures has evolved a lot over the last few decades. DHS has been the gold standard in the treatment of intertrochanteric fractures for a long period of time. Introduction of cepalomedullary nails has given orthopaedic surgeons newer options in the management of thease fractures, especially the unstable ones. Different types of cephalomedullary nails has been brought to market with added advantages latest one being PFNA2. In the current study an attempt has been made to compare the radiological and functional outcome in patients subjected to surgical treatment with DHS and PFNA2.

The age of the patients in the present study ranged from 46 to 80 years with mean age of 63.95 years which is comparable to other to other studies. ${ }^{18,19}$ Majority of the patients enrolled were females $(56.2 \%)$ which may be due to the fact that life expectancy of females is higher. The main mechanism of injury was domestic fall in elderly (78\%) and lesser common causes were road traffic accident and fall from height.

\section{Radiological union}

The current study shows a significant difference in the no. of fractures united when compared at 3 months ( $\mathrm{P}$ value $=0.001)$ as well as 6 months $(<0.01)$, suggesting that union is significantly earlier in PFNA2 nailing than in dynamic hip screw fixation. This finding was in contrast to the study conducted by Venkatesh et al where in there was no significant difference in the time to union among the two groups in which the comparison was between DHS and PFN as against PFNA2 which was the choice of implant for the current study. Another plausible reason could be the higher mean age of patients in the DHS group.
The overall functional outcome of patients having intertrochanteric fractures treated by PFNA2 is significantly better than those treated by DHS fixation. The average Harris hip score compared at the end of 1 month and 6 months conducted by Ujjal Bhakat et al as shown in Table 4 shows comparable results. ${ }^{20}$

Classification of functional outcome based on Harris Hip score, it was observed that there was $50 \%$ (24) good, $22.9 \%$ (11) fair, $27 \%$ (13) poor outcomes with DHS when compared to $12.5 \%$ (6) excellent, $75 \%$ (36) good and $12.5 \%$ (6) fair results with PFNA2 which clearly shows that PFNA2 gives better functional outcome when compared to DHS. In a study conducted by Mohammed Faisal and Prithviraj showed an excellent outcome of $66 \%$, good outcome of $28 \%$, fair outcome of $6 \%$ for PFNA2 and excellent outcome of $36 \%$, good outcome of $54 \%$, fair outcome of $8 \%$, poor outcome of $2 \%$ for DHS. ${ }^{21}$

Functional outcome can be influenced by the type of fracture. The current study had also compared the functional outcome among stable and unstable fractures in the two groups. Among the 48 cases of proximal femoral nailing 14 were unstable intertrochanteric fractures. Among the 14 intertrochanteric fractures $78.5 \%$ (11) good and $21.4 \%$ (3) fair outcomes were observed. 13 patients were having unstable fractures in the DHS group $(n=48)$, of which $7 \%$ (1) good, $53.8 \%$ (7) fair and $38.4 \%$ (5) poor outcomes. This suggests that for unstable fractures PFNA2 is a far better implant than DHS. Similar findings were also observed in a study done by Karnam et al. ${ }^{19}$

Table 4: Study by Bhakat, Ranadeb on functional outcome using PFN or DHS. ${ }^{20}$

\begin{tabular}{|l|llll|}
\hline & DHS & & PFN \\
& $\begin{array}{l}\text { Bhakat } \\
\text { et al }\end{array}$ & $\begin{array}{l}\text { Current } \\
\text { study }\end{array}$ & $\begin{array}{l}\text { Bhakat } \\
\text { et al }\end{array}$ & $\begin{array}{l}\text { Current } \\
\text { study } \\
\text { (PFNA2) }\end{array}$ \\
\hline $\begin{array}{l}\text { 1 } \\
\text { month }\end{array}$ & 24.5 & 36.21 & 35.23 & 46.31 \\
\hline $\begin{array}{l}\text { 6 } \\
\text { months }\end{array}$ & 78.8 & 71.48 & 82.8 & 81.06 \\
\hline
\end{tabular}

\section{Limitations}

The mean age of the patients in the DHS group was higher when compared to the PFNA2 group which was due to the implant selection based on the surgeon's choice. The follow up period was only 6 months. A longer follow up may have produced a comparable outcome among the two groups especially among the stable fractures.

\section{CONCLUSION}

PFNA2 gives a better functional outcome when compared to DHS. Even though DHS gives good functional outcome in stable fractures it is not so in the case of unstable fractures. The radiological union also is faster with proximal femoral nailing. Hence in our opinion PFNA2 
can be the better fixation device compared to DHS especially in unstable fractures.

Funding: No funding sources

Conflict of interest: None declared

Ethical approval: The study was approved by the institutional ethics committee

\section{REFERENCES}

1. Rathod J, Tijoriwala P. A study of results of fixation of pertrochanteric femur fractures with dynamic hip screw (DHS) \& comparision with past studies. Int J Orthopaed Sci. 2019;5(3):141-7.

2. Hinton RY, Smith GS. The association of age, race, and sex with the location of proximal femoral fractures in the elderly. J Bone Joint Surg. 1993;75(5):752-9.

3. Jiang HX, Majumdar SR, Dick DA, Moreau M, Raso J, Otto DD, et al. Development and initial validation of a risk score for predicting in-hospital and 1-year mortality in patients with hip fractures. J Bone Min Res. 2005;20(3):494-500.

4. Ngobeni RS. Mortality in elderly patients with intertrochanteric fractures: three years' experience. SA Orthop J. 2010;9(1):55-60.

5. Choudhari P, Chhabra S, Kiyawat V. Evaluation of results of titanium elastic nailing system in paediatric lower extremity fractures of long bones. J Evol Medic Dent Sci. 2014;3(72):15303-10.

6. David A, Von Der heyde D, Pommer A. Therapeutic possibilities in trochanteric fractures. Orthopaedics. 2000;29(4):294-30

7. Jonnes $\mathrm{C}, \mathrm{Sm} \mathrm{S}$, Najimudeen S. Type II Intertrochanteric Fractures: Proximal Femoral Nailing (PFN) Versus Dynamic Hip Screw (DHS). Arch Bone Jt Surg. 2016;4(1):23-8.

8. CK Yong, CN Tan, R Penafort, DA Singh, MV Varaprasad; Dynamic Hip Screw Compared to Condylar Blade Plate in the Treatment of Unstable Fragility Intertrochanteric Fractures. Mal Orthopaed J. 2009;3(1).

9. Kumar N, Kataria H, Yadav C, Gadagoli BS, Raj R. Evaluation of proximal femoral locking plate in unstable extracapsular proximal femoral fractures: Surgical technique \& mid term follow up results. J Clin Orthop Trauma. 2014;5(3):137-45.

10. Sharma V, Babhulkar S, Babhulkar S. Role of gamma nail in management of pertrochanteric fractures of femur. Ind J Orthop. 2008;42(2):212-6.
11. Hohendorff B, Meyer P, Menezes D, Meier L, Elke R. Treatment results and complications after PFN osteosynthesis. Der Unfallchirurg. 2005;108(11):938-40.

12. Socci AR, Casemyr NE, Leslie MP, Baumgaertner MR. Implant options for the treatment of intertrochanteric fractures of the hip: rationale, evidence, and recommendations. Bone Joint J. 2017;99-B(1):128-33.

13. Raviraj A, Anand A, Chakravarthy M, Pai S. Proximal femoral nail antirotation (PFNA) for treatment of osteoporotic proximal femoral fractures. Eur J Orthop Surg Traumatol. 2012;22:301-5.

14. Santharam B, Mohammed KF, Ratnam S, Madhav A. A comparative study of intertrochanteric fractures of hip treated with PFN \& PFNA 2.

15. Kyavater BS, Gupta S. Comparative study between dynamic hip screw vs Proximal femoral nailing in unstable inter-trochanteric fractures of the Femur in adults. J Evol Medic Dent Sci. 2015;4(50):8690-4.

16. Boyd HB. GRIFFIN "classification and treatment of trochanteric fractures". Arch Surg. 1949;58:853-66.

17. Harris WH. Traumatic arthritis of the hip after dislocation and acetabular fractures: treatment by moldarthroplasty. An end-result study using a new method of result evaluation. J Bone Joint Surg Am. 1969;51(4):737-55

18. Kumar R, Singh RN, Singh BN. Comparative prospective study of proximal femoral nail and dynamic hip screw in treatment of intertrochanteric fracture femur. J Clin Orthop Trauma. 2012;3(1):2836.

19. Karanam V, Kumar UA, Dr, Teja S, Teja CB. PFn v/s DHs in stabilization of interochanteric fractures: A Comparative study. Int J Orthopaed Sci. 2019; 5(2):750-4.

20. Bhakat U, Bandyopadhayay R. Comparitive Study between Proximal Femoral Nailing and Dynamic Hip Screw in Intertrochanteric Fracture of Femur. Open J Orthop. 2013; 03(07):291-5.

21. Faisal, Mohammad, Nistane, Prithviraj. Proximal Femoral Nailing vs. Dynamic Hip Screw in unstable Intertrochanteric Fracture of Femur-a comparative analysis. Int J Biomedic Advan Res. 2016.

Cite this article as: Chandy G, Saju S. A comparative study on the functional outcome of intertrochanteric fractures treated by proximal femoral nailing or dynamic hip screw fixation. Int $\mathbf{J}$ Res Orthop 2021;7:51-5. 